se observa con claridad como la mitra del San Eugenio ha sido restaurada en parte, en los talleres alicantinos, como indica la documentación. Más de taller sería el escudo de armas del cardenal Aragón sobre el que ya hemos indicado no nos atrevemos a pronunciarnos. Habrá que esperar la feliz circunstancia de que un documento aparecido en Toledo, Alicante o Génova nos desvele la paternidad de estas nuevas esculturas genovesas aparecidas en España.

Un último asunto en extremo problemático y sobre el que minuciosamente ha trabajado José María Prados, nos queda por plantear, el de la formación de Narciso Tomé, tema aún sin resolver y sobre el que se abren un gran número de interrogantes. Creemos que estas obras italianas influyen en su obra, las Santas Leocadia y Casilda del primer cuerpo del Transparente ofrecen elementos claramente tomados de ellas, a pesar de su más avanzada fecha y de su entronque ya con el rococó. Pero además, hay en la escultura genovesa del barroco una serie de elementos que aparecen, aunque con un evolucionado sello personal, en la obra de Narciso Tomé. Los símbolos angélicos del púlpito de la iglesia genovesa de San Siro, singularmente el ángel de San Mateo, y los ángeles que adornan los ángulos laterales del altar mayor de la capilla de Villa Cattaneo de una gracia plenamente rococó, por citar sólo dos ejemplos de los muchísimos que abundan, muestran unas alas que se adosan al mármol del fondo de manera sinuosa y tentacular al modo típico de un Tomé. Lo mismo cabe decir de la gracia, en realidad también rococó, de los ángeles laterales del altar mayor de la iglesia de San Siro, el que se ha dicho el más hermoso altar de Génova ${ }^{23}$, cuyo movimiento de danza parece pudieron inspirar figuras que Tomé repetirá, por ejemplo, en la peana de la custodia de la catedral ${ }^{24}$. Los espléndidos trabajos de mármoles de colores en solados y revestimientos de capillas también llevan a pensar en trabajos de Tomé que muy difícilmente pudo haberlos estudiado sin salir de la península. Nada definitivo podemos apuntar pero creemos que es una pista más a tener en cuenta al juzgar la obra española, inserta plenamente en el más selecto barroco europeo, de este genial artista toresano que enraizará en el mundo artístico y social toledano de la primera mitad del siglo xviII.

Juan Nicolau Castro

Dr. por la Universidad Autónoma

\title{
NUEVAS OBRAS DE ANTONIO MOHEDANO Y FRANCISCO VARELA
}

El estudio de la pintura sevillana del primer tercio del siglo xviI contó en 1985 con un riguroso trabajo de recopilación y catalogación realizado por Enrique Valdivieso y Juan Miguel Serrera ${ }^{1}$ que ha servido para que buena parte de los estudiosos de este período, puedan seguir avanzando en sus investigaciones.

Entre los artistas de este momento que se estudian, en la citada obra, se abordan las personalidades de Antonio Mohedano y Francisco Varela, artistas a cuyos catálogos podemos añadir ahora dos nuevas obras.

23 Belloni, Item, pág. 131.

24 Prados, J. M.: “El proyecto de Narciso Tomé para la peana de la custodia de la catedral de Toledo», Archivo Español de Arte, n. ${ }^{\circ} 201,1978$, pág. 101.

1 Valdivieso, E. y Serrera, J. M.: Pintura sevillana del primer tercio del siglo XVII, Madrid, CSIC, 1985. 
Recientemente en el mercado de arte madrileño comparecía una espléndida Sagrada Familia con San Juanito 127 x 106,5 cms que se catalogaba como obra anónima de escuela española o italiana siglos XVII-XVIII ${ }^{2}$. Se trata sin duda alguna de obra del pintor nacido en Antequera y formado en Córdoba y Sevilla, Antonio Mohedano de la Gutierra (1561-63-1626) (fig. 14), artista probablemente discípulo de Pablo de Céspedes y con resonancias evidentes de lo que se hacía en Italia a fines del XVI y primerísimos años del xvII. Esta nueva obra que ahora presentamos, de composición piramidal y rigurosamente simétrica, compensada a un lado por San José con la palma y a otro con San Juanito y el cordero bajo el estrado, repite en cuanto a composición y modelos la Sagrada Familia con San Joaquín y Santa Ana del Museo de Bellas Artes de Sevilla ${ }^{3}$ (fig. 15), obra segura de Mohedano pero de mayor dureza que la que ahora presentamos. Tanto la figura de San José con la palma, así como la Virgen con el niño siguen los modelos de la del Museo sevillano, aunque el rostro de la Virgen más delicado en esta nueva obra lleva el velo de una manera más sutil que el que muestra aquella. Otra diferencia es el mayor tamaño de la del Museo sevillano 193 x $118 \mathrm{cms}$, lo que hace que presente en la parte superior un rompimiento de gloria. Es interesante advertir los detalles naturalistas que aparecen en primer término del lienzo ahora presentado. Las delicadas flores así como el cordero, anticipan los detalles primorosos y naturalistas de Zurbarán, lo que acentúa aún más la importancia de esta obra pues su fecha antecede en mucho a la del pintor extremeño. Podría situarse hacia 1605-10 en fecha próxima a la repetidamente citada Sagrada Familia del Museo sevillano y a la Anunciación del retablo de la Casa Profesa de Sevilla, hoy Iglesia de la Anunciación. El retablo de esta iglesia se realiza entre 1605-7 y tanto las facciones de la Virgen como el semblante de los niños del rompimiento de gloria de la Anunciación se relacionan muy directamente con la Sagrada Familia con San Juanito. Por otro lado la tonalidad rosada que inunda toda la composición, recordando el colorido de Maino, nos trae nuevamente a colación las relaciones con lo italiano y con el manierismo reformado; artistas formados en la tradición manierista pero que se inclinan levemente por el lenguaje de la verosimilitud ${ }^{4}$, creando y transmitiendo una atmósfera íntima, con detalles naturalistas, como el jarrón que se sitúa detrás del San Juanito o las aludidas flores del primer término.

Pacheco celebró los azules claros de Mohedano ${ }^{5} \mathrm{y}$ esta obra es buena prueba de ello, pudiéndose considerar como una de sus más importantes pinturas hasta ahora dadas a conocer.

Estas relaciones establecidas con lo italiano por su clasicismo en la composición y su cálido colorido nos traen indudables paralelismos con la obra de los «Manieristas reformados» italianos como Santi di Tito, aunque hemos de pensar también en la influencia de los modelos escurialenses a través de Zuccaro y sus discípulos. La obra de Pablo de Céspedes, maestro suyo según nos informa Palomino ${ }^{6}$, puede ser un buen ejemplo para entender el rigor y la simplicidad en las composiciones como evidencia la Santa Ana y la Virgen de Céspedes del Monasterio de Guadalupe $^{7}$. Posteriormente la obra de Mohedano se inclinaría a copiar modelos ajenos, como

\footnotetext{
2 Subastas Fernando Durán: Gran subasta de inauguración de temporada, 17 de octubre de 1995, pág. 100 , lote 359.

3 La obra fue dada a conocer por Diego Angulo Iñíguez: "Pintura del siglo XVII", en Ars Hispaniae, Madrid, 1971, t. $\mathrm{XV}$, pág. 86. Posteriormente fue estudiada con un sentido puramente descriptivo por Rafael González Zubieta: Vida y obra del artista andaluz Antonio Mohedano de la Gutierra, 1563?-1626, Córdoba, 1981, págs. 170 y 207 . Posteriormente se recoge y estudia en Valdivieso-Serrera: Pintura sevillana..., op. cit., 1985, pág. 184, n. 8, lám. 148. Posteriormente en Rocío Izquierdo y Valme Muñoz: Museo de Bellas Artes inventario de pinturas, Sevilla, 1990, pág. 97, n. Inv. 100. Finalmente, véase: Obras maestras del Museo de Bellas Artes de Sevilla, siglos XV-XVIII, Sevilla, Focus, 1992, págs. 90-91, cat. 17.

4 Pérez Sánchez, A. E.: "La crisis de la pintura española en torno a 1600», en España en las crisis del arte europeo, Madrid, CSIC, 1968.

5 Pacheco, F.: Arte de la Pintura, Madrid, Ed. de Bonaventura Bassegoda, 1990, pág. 486.

6 Palomino, A.: Museo pictórico y escala óptica con el Parnaso español pintoresco y laureado, Madrid, Ed, 1947, pág. 839.

7 Esta obra que ha pasado inadvertida para buena parte de la crítica es pieza indudable de Pablo de Céspedes como demostró en su día Alfonso E. Pérez Sánchez: "Céspedes de Guadalupe», en Archivo Español de Arte, 1971, págs. $338-41$.
} 

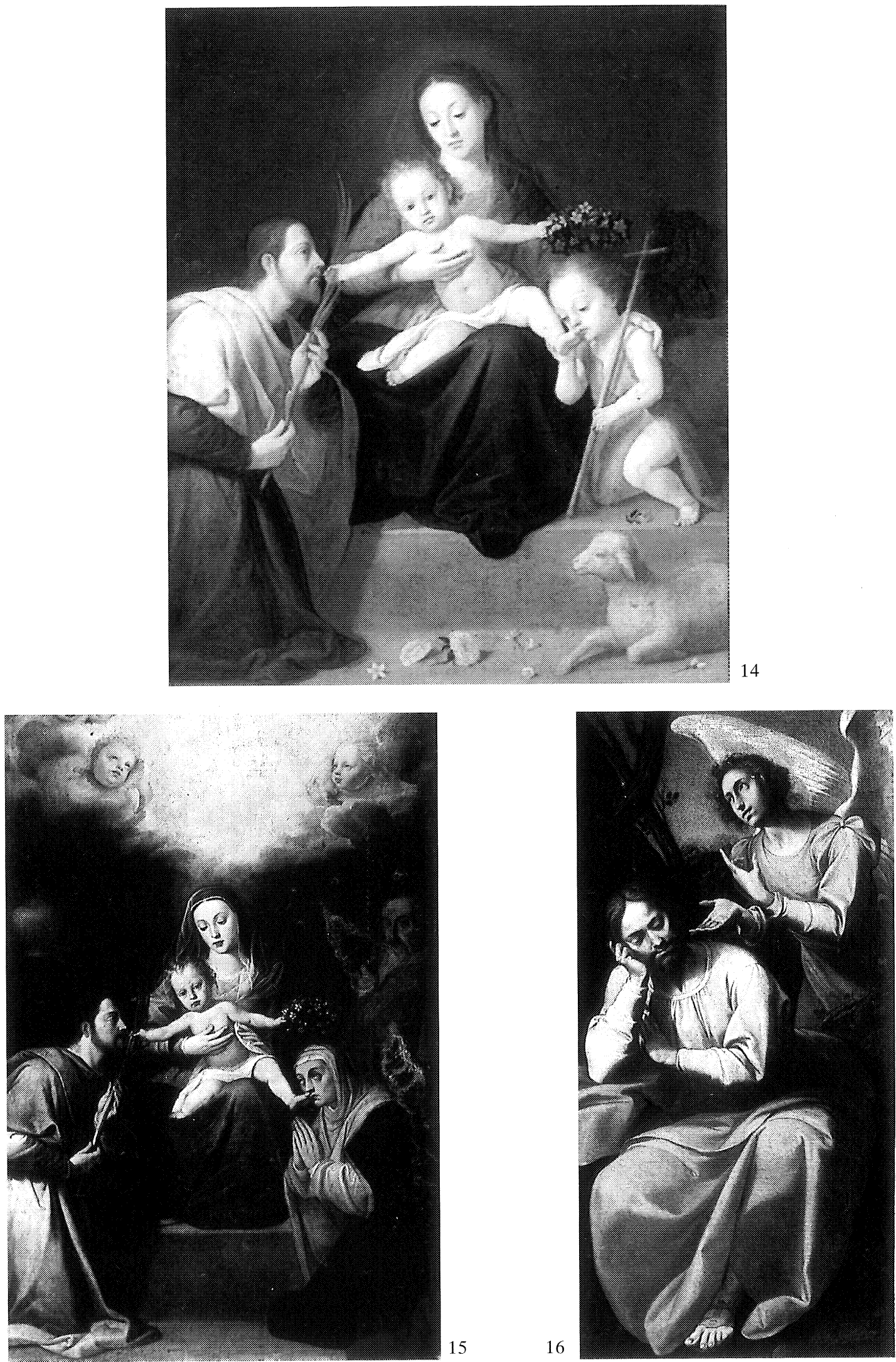

Fig. 14. Antonio Mohedano: Sagrada Familia con San Juanito. Madrid, mercado de arte.

Fig. 15. Antonio Mohedano: Sagrada Familia con San Joaquín y Santa Ana. Sevilla. Museo de Bellas Artes.

Fig. 16. Francisco Varela: Sueño de San José. Foto Archivo Moreno. Antigua Colección Weisberger. 
son las estampas de Cornelis Cort, concretamente la Anunciación con Profetas según modelo de Zuccaro que copia en la Alegoría de la Inmaculada y Nacimiento de Cristo de la Iglesia de San Juan de Antequera.

Otro artista significativo de este primer tercio del siglo xvi sevillano y que también se inclina por la verosimilitud, cuyo catálogo es igualmente reducido, es Francisco Varela (ca. 1585-1645). Su obra de clara ascendencia manierista, se configura por el seguimiento de estampas y por una primera aproximación a aspectos «naturalistas». La pintura que ahora damos a conocer representa El Sueño de San José (fig. 16) perteneció a la colección Weisberger de Madrid y fue erróneamente atribuida a Zurbarán por Ramón Torres Martín ${ }^{8}$. La obra, que conozco sólo a través de fotografía perteneciente al Archivo Moreno sito en el ICRBC, presenta en el ángulo inferior derecho la firma siguiente: «Var... $f$ año 1642.» Por su estilo y sus evidentes relaciones con el Cristo de la Cena de la Iglesia de San Bernardo de Sevilla, obra firmada por Varela en 1622, podemos asegurar que se trata de obra de este artista, además del característico movimiento de paños y tratamiento manierista de la escena que llena todo el cuadro.

Otra relación indudable con Varela aparece en el manto que cubre las piernas de San José y la manera de realizar el pie de éste pues son virtualmente idénticas al modo en como Varela realizó los plegados y pie de su San Juan evangelista de las Teresas de Sevilla ${ }^{9}$ obra datada por Valdivieso-Serrera en 1630. Esto nos indica, como ya apuntaron estos autores, lo poco evolucionado que resulta el estilo de Varela pues desde 1622 a 1642 en que fecha esta nueva obra sus modelos, ambiente y pincelada permanecen casi invariables.

Benito Navarrete Prieto Universidad de Valencia

\section{UN VULTUS TRIFRONS INEDITO: EL SEPULCRO DE DOÑA ELVIRA DE NOBOA EN LA IGLESIA DE SAN FRANCISCO DE ORENSE *}

Oh quanto parve a me gran maraviglia, quando'io vidi tre face a la sua testa!

INFIERNO

La iglesia del convento de San Francisco, de Orense -de azarosa historia- presenta como valor añadido a su hermosa arquitectura el servir de panteón para algunos representantes de una noble estirpe de la provincia: los Noboa, de la casa de Maceda, cuya influencia determinó la propia existencia del edificio ${ }^{1}$.

8 Torres Martín, R.: Zurbarán, el pintor gótico del siglo XVII, Sevilla, 1963, cat. 256. Obra carente de todo rigor científico.

9 Valdivieso-Serrera: Pintura sevillana, op. cit., 1985, lám. 180. Para reafirmar la relación estilística de esta obra con la que ahora damos a conocer, obsérvense las semejanzas en la manera de solucionar los troncos arbóreos y las hojas en penumbra.

* Esta nota forma parte de un trabajo de investigación dirigido por la profesora Clara Delgado Valero.

1 Sobre las relaciones de los Noboa con el convento véanse los trabajos anónimos: «Documentos relativos al Convento de San Francisco de Orense», Bol. Com. Monum. Orense, VI, 1921, 339-43, y «Breve del Papa Bonifacio VIII", Ibidem, IX, 1934, 265-267. 